\title{
Study of Serum Superoxide Dismutase and Malondialdehyde Levels during Normal Pregnancy
}

\author{
${ }^{1}$ Roopam Bassi, ${ }^{2}$ Saurabh Sharma, ${ }^{3}$ Kiran Mehta, ${ }^{4}$ Manjeet Kaur, ${ }^{5}$ Deepinder Kaur
}

\begin{abstract}
Introduction: Pregnancy is accompanied by a high-energy demand of all body functions and an increased oxygen requirement, which can give rise to increased levels of oxidative stress.
\end{abstract}

Aims and objectives: The present study was done to assess the levels of oxidative stress in healthy pregnant females by estimating serum superoxide dismutase (SOD) and malondialdehyde (MDA) levels and comparing these with nonpregnant females.

Materials and methods: The study was conducted on 88 female subjects in the age group of 20 to 40 years, who were placed in two groups. Group I consisted of 50 healthy nonpregnant females. Group II consisted of healthy pregnant females further subdivided into three subgroups: Group Ila (1st trimester) $n=38$, group IIb (2nd trimester) $n=32$, and group Ilc (3rd trimester) $n=30$. The same subjects were followed up till the 3rd trimester. There was a drop in the number of subjects from 38 to 32 in the 2nd trimester and from 32 to 30 in the 3rd trimester due to noncompliance and development of complications of pregnancy. The subjects were assessed for hemoglobin ( $\mathrm{Hb})$, MDA, a marker for lipid peroxidation, and SOD, an antioxidant enzyme along with certain physiological parameters like height, weight, body mass index, and blood pressure in the three trimesters.

Results: The levels of SOD and MDA were significantly raised with the progression of pregnancy. There was a fall in $\mathrm{Hb}$ levels in the 3rd trimester. But no significant correlation could be drawn between the measured parameters in all the trimesters.

Conclusion: Pregnancy is definitely associated with oxidative stress to the body. Both peroxidation and antioxidation reactions are enhanced during pregnancy. With these findings, we therefore conclude that antioxidant supplements should be prescribed in early pregnancy to prevent the overwhelming of oxidative stress in pregnant females.

Keywords: Malondialdehyde, Pregnant females, Superoxide dismutase.

\footnotetext{
${ }^{1-5}$ Professor

1,3-5 Department of Physiology, Sri Guru Ram Das Institute of Medical Sciences and Research, Amritsar, Punjab, India

${ }^{2}$ Department of Dermatology and Venereology, Sri Guru Ram Das Institute of Medical Sciences and Research, Amritsar Punjab, India

Corresponding Author: Roopam Bassi, Professor, Department of Physiology, Sri Guru Ram Das Institute of Medical Sciences and Research, Amritsar, Punjab, India, Phone: +919872477997 e-mail: drroopamsharma@yahoo.co.in, drsaurabhsharma@ yahoo.co.in
}

How to cite this article: Bassi R, Sharma S, Mehta K, Kaur M, Kaur D. Study of Serum Superoxide Dismutase and Malondialdehyde Levels during Normal Pregnancy. Curr Trends Diagn Treat 2017;1(1):1-5.

Source of support: Nil

Conflict of interest: None

\section{INTRODUCTION}

Increased free radical formation in the body is called oxidative stress. Free radicals, such as hydroxyl, superoxide, and nitric oxide $(\mathrm{NO})$ derived from molecular oxygen and nitrogen are highly reactive metabolites and are called reactive oxygen species (ROS). ${ }^{1,2}$

In healthy individuals, the presence of a wide range of antioxidant systems either limits the production of ROS or inactivates them, thereby repairing cell damage and maintaining homeostasis. Excess production of oxidants results in oxidative stress-induced cellular damage, degeneration, and mutagenesis. ${ }^{3}$ The effect of oxidative stress is seen throughout the reproductive phase of a woman and also during menopause. The ROS influences multiple processes ranging from maturation of oocyte to fertilization, development of embryo and pregnancy, and parturition. ${ }^{4}$ Physiological levels of ROS like NO, carbon monoxide, superoxide anion, etc., are involved in the proliferation and differentiation of the trophoblastic tissue and vascular reactivity. Oxidative processes also have an impact on maternal cardiovascular system, resulting in an increase in the blood volume and cardiac output, and a decrease in the systemic blood pressure. ${ }^{5}$

Pregnancy, being a physiological state, is accompanied by a high-energy demand of many body functions and an increased oxygen requirement because of which augmented levels of oxidative stress would be expected. ${ }^{6}$ Free radical oxidation during pregnancy becomes activated. The intensity of oxidative stress adjusts to the dynamic physiology, mother's body weight, and changes of blood lipid concentration. ${ }^{7}$ This oxidative stress causes increase in lipid peroxidation products, but this peroxidation is balanced by adequate antioxidative responses. ${ }^{8}$ The activity of the antioxidant enzyme superoxide dismutase (SOD) increases throughout pregnancy. This occurs in response to normal oxidative stress due to pregnancy. ${ }^{9}$ 
Oxidative stress results because of the presence of placenta, which is rich in mitochondria. Fully developed placenta consumes about $1 \%$ of the basal metabolic rate of the pregnant woman. It is also highly vascular and is exposed to high maternal oxygen partial pressure. Pregnancy is characterized by increased basal oxygen consumption and changes in energy substrate use by different organs. These features support the generation of superoxide, as $5 \%$ of all electrons in the mitochondrial electron transport chain leak out of the mitochondria. ${ }^{10}$ Nitric oxide, which is locally produced by the placenta along with other reactive nitrogen species, contributes to oxidative stress. ${ }^{11}$

Various protective mechanisms develop against free radical generation and damage during pregnancy, but the degree of oxidative stress depends on the balance between the defense mechanisms and the free radical-producing mechanisms. The mean serum malondialdehyde (MDA) levels in the antenatal subjects in the 2nd trimester are significantly higher than in the 1st trimester. Pregnancy is a physiological condition in which women are prone to oxidative stress due to imbalance between prooxidant and antioxidant factors. ${ }^{12}$

The present study was done to assess the oxidative stress in healthy pregnant females, by estimating serum SOD and MDA levels and comparing these with nonpregnant females.

\section{MATERIALS AND METHODS}

For our study, healthy pregnant females in their 1st trimester attending the antenatal clinic of the Department of Obstetrics and Gynecology in a tertiary care hospital in Amritsar were taken as subjects. Various physiological and biochemical parameters were assessed in the Department of Physiology in collaboration with the Department of Biochemistry. The appropriate institutional board approved the protocol used in this study, and all subjects gave informed consent.

The study was conducted on 88 female subjects in the age group of 20 to 40 years, of whom 50 were healthy nonpregnant females who served as controls. A total of 38 pregnant females who were in their 1st trimester of pregnancy were selected and were subsequently followed up in their 2nd and 3rd trimesters.

\section{Exclusion Criteria}

Those with established medical risk factors for oxidative stress, such as preeclampsia, acquired immune deficiency syndrome, diabetes, tuberculosis, smoking, and alcohol consumers were excluded from the study. Subjects taking antioxidant drugs were also excluded from the study. A detailed history including obstetric history was taken. A complete general and physical examination was done. The subjects were screened for routine investigations like hemoglobin $(\mathrm{Hb})$, total leukocyte count, differential leukocyte count, and blood group. They were assessed for SOD and MDA levels in the three subsequent trimesters of pregnancy to find any oxidative stress in normal pregnancy.

The subjects were divided into the following groups: Group I - 50 healthy nonpregnant females; group II healthy pregnant females further subdivided into three subgroups: Group IIa (1st trimester) $\mathrm{n}=38$, group IIb (2nd trimester) $n=32$, and group IIc (3rd trimester) $n=30$. The same subjects were followed up till the 3 rd trimester. There was a drop in the number of subjects from 38 to 32. This was due to noncompliance of the study by three subjects and development of complications of pregnancy in the other three subjects. The number again dropped in the 3rd trimester to 30, which was due to the development of preeclamptic signs and symptoms. The subjects were assessed for $\mathrm{Hb}, \mathrm{MDA}$, and SOD along with certain physiological parameters, such as height, weight, body mass index, and blood pressure in the three trimesters.

Fasting blood samples were taken and the following parameters were estimated in both cases and controls:

- Serum MDA levels ${ }^{13}$

- Serum SOD levels ${ }^{14,15}$

\section{Statistical Analysis}

Statistical analysis was done by using one-way analysis of variance with post hoc Tukey honest significant difference comparing mean values of all the variables between the four groups. The difference was considered significant if $p<0.05$ and highly significant if $p<0.001$. The data were analyzed, and valid conclusions were drawn. Statistical Package for the Social Sciences (SPSS) 17.0 software was used.

\section{RESULTS}

Table 1 shows a gradual fall in $\mathrm{Hb}$ values from 1st to 3rd trimester. But this change is not significant when compared with the trimesters or when compared with the controls (Table 2). Superoxide dismutase levels show a significant rise throughout the three trimesters. This increase was significant in the 1st and 3rd trimester as compared with controls. The increase in MDA was significant in all the three trimesters as compared with controls. In Table 2, the increase in systolic blood pressure (SBP) was significant in the 2nd and 3rd trimester, and the diastolic blood pressure (DBP) showed a significant fall in the 3rd trimester. Table 3 shows the $p$ values of the intertrimesteric comparison. The fall in $\mathrm{Hb}$ values was seen to be highly significant. The rise in SOD levels 
Study of Serum Superoxide Dismutase and Malondialdehyde Levels during Normal Pregnancy

Table 1: Mean \pm standard deviation of all the groups

\begin{tabular}{lllll}
\hline & Group I $(n=50)$ & Group I/a $(n=38)$ & Group IIb $(n=32)$ & Group I/c $(n=30)$ \\
\hline $\mathrm{Hb}(\mathrm{g} / \mathrm{dL})$ & $9.96 \pm 1.48$ & $10.63 \pm 1.21$ & $10.02 \pm 1.11$ & $8.92 \pm 1.15$ \\
$\mathrm{SOD}(\mathrm{U} / \mathrm{mL})$ & $2.84 \pm 0.56$ & $2.40 \pm 0.50$ & $2.99 \pm 0.57$ & $4.34 \pm 1.10$ \\
$\mathrm{MDA}(\mathrm{nmol} / \mathrm{L})$ & $1.62 \pm 0.49$ & $3.68 \pm 3.75$ & $3.41 \pm 0.78$ & $4.51 \pm 1.03$ \\
$\mathrm{SBP}(\mathrm{mm} \mathrm{Hg})$ & $117.48 \pm 7.08$ & $115.58 \pm 7.79$ & $123.38 \pm 6.61$ & $130.53 \pm 6.05$ \\
$\mathrm{DBP}(\mathrm{mm} \mathrm{Hg})$ & $78.00 \pm 4.57$ & $79.45 \pm 3.21$ & $74.94 \pm 4.53$ & $70.53 \pm 4.45$ \\
\hline
\end{tabular}

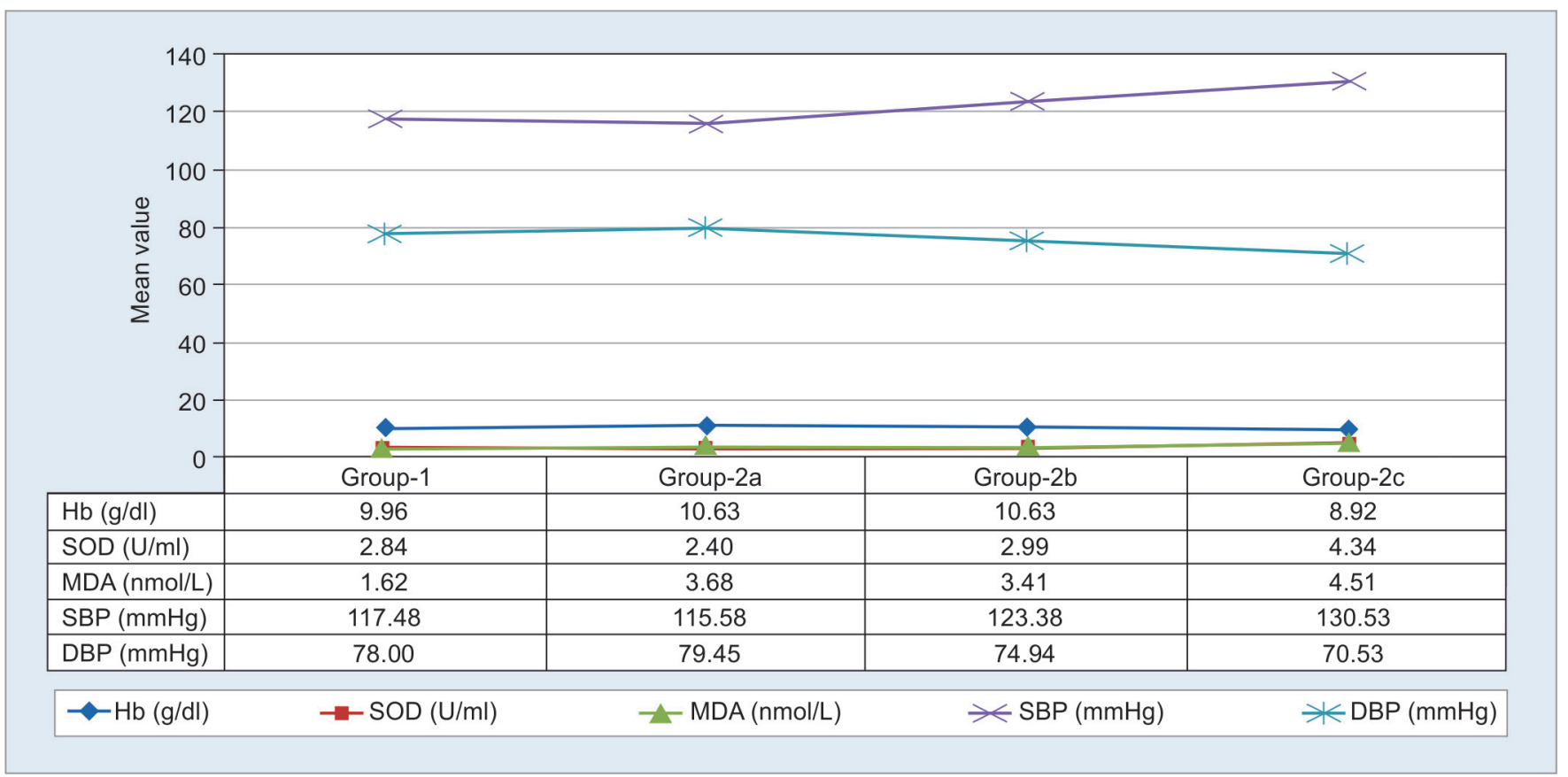

Table 2: Comparison ( $p$ values) between group I (controls) and group II (pregnant subjects)

\begin{tabular}{llll}
\hline & $\begin{array}{l}\text { Groups I } \\
\text { and Ila }\end{array}$ & $\begin{array}{l}\text { Groups I } \\
\text { and IIb }\end{array}$ & $\begin{array}{l}\text { Groups I } \\
\text { and IIc }\end{array}$ \\
\hline $\mathrm{Hb}$ & $0.026^{*}$ & 0.832 & $0.002^{*}$ \\
$\mathrm{SOD}$ & $0.000^{* *}$ & 0.226 & $0.000^{* *}$ \\
$\mathrm{MDA}$ & $0.000^{* *}$ & $0.000^{* *}$ & $0.000^{* *}$ \\
$\mathrm{SBP}$ & 0.236 & $0.000^{* *}$ & $0.000^{* *}$ \\
$\mathrm{DBP}$ & 0.100 & $0.004^{*}$ & $0.000^{* *}$ \\
\hline
\end{tabular}

${ }^{*} p<0.05$ : Significant; ** $p<0.001$ : Highly significant

Table 3: Comparison ( $p$ values) within group II

\begin{tabular}{llll}
\hline & $\begin{array}{l}\text { Between } \\
\text { groups Ila } \\
\text { and IIb }\end{array}$ & $\begin{array}{l}\text { Between } \\
\text { groups Ila } \\
\text { and Ilc }\end{array}$ & $\begin{array}{l}\text { Between } \\
\text { groups IIb } \\
\text { and Ilc }\end{array}$ \\
\hline $\mathrm{Hb}$ & $0.000^{* *}$ & $0.000^{* *}$ & $0.000^{* *}$ \\
SOD & $0.001^{*}$ & $0.000^{* *}$ & $0.000^{* *}$ \\
MDA & 0.492 & $0.003^{*}$ & $0.000^{* *}$ \\
SBP & $0.000^{* *}$ & $0.000^{* *}$ & $0.000^{* *}$ \\
DBP & $0.000^{* *}$ & $0.000^{* *}$ & $0.000^{* *}$ \\
\hline
\end{tabular}

${ }^{*} p<0.05$ : Significant; ${ }^{* *} p<0.001$ : Highly significant

was highly significant throughout the three trimesters. Malondialdehyde levels showed highly significant rise in the 3rd trimester. Changes in SBP and DBP were also highly significant.
Table 4: Correlation within group I

\begin{tabular}{lll}
\hline & $S O D$ & MDA \\
\hline Hb & $r=0.158 ; p=0.272$ & $r=0.026 ; p=0.857$ \\
SOD & - & $r=0.458^{* *} ; p=0.001$ \\
\hline
\end{tabular}

${ }^{*} p<0.05$ : Significant; ${ }^{* *} p<0.01$ : Highly significant

Tables 4 and 5 show the correlation coefficients between the various groups. Within group I (Table 4), no significant correlation could be seen among the various parameters. Table 5 depicts the correlation coefficients within group II subjects. No significant positive or negative correlation could be drawn.

\section{DISCUSSION}

Pregnancy is a condition exhibiting increased susceptibility to oxidative stress, defined here as a disturbance in the prooxidant-antioxidant balance in favor of the former, leading to potential damage. ${ }^{16,17}$ It was observed during our study that the mean serum SOD levels showed a highly significant $(p<0.001)$ increase during all the three trimesters. Our findings are supported by a study by Gitto et al $^{18}$ which demonstrated that SOD activity gradually increased in the group of pregnant $v$ s nonpregnant women. Another study by Desai et $\mathrm{al}^{6}$ revealed high levels 
Table 5: Correlation within group II

\begin{tabular}{|c|c|c|c|c|c|c|}
\hline & \multicolumn{2}{|c|}{ Group IIa } & \multicolumn{2}{|c|}{ Group IIb } & \multicolumn{2}{|c|}{ Group I/c } \\
\hline & $S O D$ & $M D A$ & $S O D$ & $M D A$ & $S O D$ & $M D A$ \\
\hline $\mathrm{Hb}$ & $\begin{array}{l}r=-0.212 \\
p=0.202\end{array}$ & $\begin{array}{l}r=0.062 \\
p=0.713\end{array}$ & $\begin{array}{l}r=-0.025 \\
p=0.891\end{array}$ & $\begin{array}{l}r=0.358 \\
p=0.044^{*}\end{array}$ & $\begin{array}{l}r=-0.087 \\
p=0.646\end{array}$ & $\begin{array}{l}r=0.061 \\
p=0.750\end{array}$ \\
\hline SOD & - & $\begin{array}{l}r=-0.246 \\
p=0.137\end{array}$ & - & $\begin{array}{l}r=0.020 \\
p=0.915\end{array}$ & - & $\begin{array}{l}r=0.124 \\
p=0.515\end{array}$ \\
\hline
\end{tabular}

${ }^{*} p<0.05$ : Significant

of serum SOD in early and late pregnancy. Pregnancy is a state of physiological stress to the body and signals for a beneficial cellular response that activates the induction of antioxidants, which further help in tissue protection and in host defense. ${ }^{19}$ This antioxidant accumulation, according to another study, has been attributed to human placenta, and this activity increases throughout gestation to prevent the deleterious effects of superoxide. ${ }^{20}$

The marker for lipid peroxidation, MDA, showed a highly significant increase in the 2nd and 3rd trimesters $(\mathrm{p}<0.001)$. This is consistent with a study where increase in lipid peroxidation occurred in serum as gestation progressed, and these findings correlate with changes in lipoperoxidation activity of placenta and with an increase in total serum lipids. ${ }^{21}$ According to another study, pregnancy is a stimulus for lipid peroxidation, and circulating peroxidation products may originate from the placenta. ${ }^{22}$ Placental tissue might be a source of lipid peroxidation products in pregnancy according to another study and that placental peroxidation activity increases throughout gestation. Malondialdehyde is a major breakdown product split off from lipid peroxides. ${ }^{23}$ Our results are further authenticated by another study, which reported higher levels of lipid hydroperoxides (LPOs) in blood and production of lipid peroxides in placenta in uncomplicated pregnancies. ${ }^{24}$ We could not draw any significant correlation between the various parameters during all the trimesters as well as in the controls.

One of the limitations of our study is the small number of subjects taken. The larger group might have been helpful in drawing some correlation between the various parameters. Second, we could have grouped the pregnant subjects separately, depending upon their parity, as primigravida and multigravida and assessed the levels of oxidative stress.

\section{CONCLUSION}

Thus, from our study, we can conclude that normal pregnancy is definitely associated with oxidative stress to the body. Both peroxidation and antioxidation reactions are enhanced during pregnancy. The LPOs gradually increase significantly toward the end of pregnancy.
As gestation advances, physiological stress to the body signals for a beneficial cellular response, which activates the induction of antioxidants, such as SOD. With these findings, we therefore conclude that antioxidant supplements should be prescribed in early pregnancy to prevent the overwhelming of oxidative stress in pregnant females.

\section{ACKNOWLEDGMENT}

Authors would like to thank the subjects for their cooperation. We especially thank our statistician Mr. Gurinder Singh for his help.

\section{REFERENCES}

1. Nair S, Gupta R. Dietary antioxidant flavonoids and coronary heart disease. J Assoc Physicians India 1996 Oct;44(10) 698-708.

2. Sharma RK, Agarwal A. Role of reactive oxygen species in gynaecological diseases. Review article. Reprod Med Biol 2004 Dec;3(4):177-199.

3. Droge W. Free radicals in the physiological control of cell function. Physiol Rev 2002 Jan;82(1):47-95.

4. Fainaru O,Almog B, Pinchuk I, Kupferminc MJ, Lichtenberg D, Many A. Active labor is associated with increased oxidisibility of serum lipids ex vivo. BJOG 2002;109:938-941.

5. Myatt L, Cui X. Oxidative stress in the placenta. Histochem Cell Biol 2004 Oct;122(4):369-382.

6. Desai P, Rathod SP, Garge V. Evaluation of pro-oxidants and antioxidants in pre-eclampsia. J Obstet Gynaecol India 2003;53(5):445-448.

7. Operaitienë V, Glempienë I, Kalpokaitë Z, Kalibatienë D. Analysis of the level of free radical lipid peroxidation and antioxidative system activity during different pregnancy weight gain and multifetal pregnancy. Acta Med Lituanica 2005;12(2):8-13.

8. Chaudhari L, Tandon OP, Vaney N, Agarwal N. Lipid peroxidation and antioxidant enzymes in gestational diabetes. Indian J Physiol Pharmacol 2003 Oct;47(4):441-446.

9. Nakai A, Oya A, Kobe H. Changes in maternal lipid peroxidation levels and antioxidant enzymatic activities before and after delivery. J Nippon Med Sch 2000 Dec;67(6):434-443.

10. Fridovich I. Hypoxia and oxygen toxicity. Adv Neurol 1979;26:255-259.

11. Dotsch J, Hogen N, Nyul Z, Hanze J, Knerr I, Kirschbaum M, Rascher W. Increase in endothelial nitric oxide synthase and endothelin - 1 mRNA expression in human placenta during gestation. Eur J Obstet Gynecol Reprod Biol 2001 Aug;97(2):163-167. 
12. Adiga U, Adiga MNS. Total antioxidant activity in normal pregnancy. Online J Health Allied Sci 2009;8(2):8.

13. Satoh K. Serum lipid peroxide in cerebrovascular disorders determined by a new colourimetric method. Clin Chem Acta 1998 Nov;90(1):37-43.

14. Marklund S, Marklund G. Involvement of superoxide anion radical in the autooxidation of pyrogallol and a convenient assay of superoxide dismutases. Eur J Biochem 1974 Sep;47(3):469-474.

15. Nandi A, Chatterjee IB. Assay of superoxide dismutases activity in animal tissue. J Biosci 1988 Sep;13(3):305-315.

16. Sies, H. Oxidative stress II. Oxidants and antioxidants. London: Academic Press; 1991.

17. Page, KR. The physiology of human placenta. London: UCL Press Limited; 1993. p. 164.

18. Gitto E, Reiter RL, Karbownik M, Tan DX, Gitto P, Barberi S, Barberi I. Causes of oxidative stress in the pre and perinatal period. Biol Neonate-Fetal Neonatal Res 2002;81(3):146-157.

19. Ray G, Hussain SA. Oxidants, antioxidants and carcinogenesis. Indian J Exp Biol 2002 Nov;40(11):1220-1221.
20. Myatt L, Eis ALW, Brockman DE, Kossenjans W, Greer IA, Lyall F. Differential localization of superoxide dismutase isoforms in placental villous tissue of normotensive, preeclamptic and intrauterine growth-restricted pregnancies. J Histochem Cytochem 1997 Oct;45(10):1433-1438.

21. Kharb S, Singh V. Total free radical trapping antioxidant potential in normal pregnancy. J Obstet Gynecol Ind 2004 May-Jun;54(3):249-250.

22. Moore, M.J. Maternal physiology during pregnancy. In: DeCherney, A.H.; Pernoll, M.L., editors. Current obstetrics and gynaecology diagnosis and treatment. 8th ed. Upper Saddle River, NJ: Prentice Hall International Inc.; 1994. p. 148-149.

23. Mihailovic M, Cvetkovic M, Ljubic A, Kosanović M, Nedeljković S, Jovanović I, Pesut O. Selenium and malondialdehyde content and glutathione peroxidase activity in maternal and cord blood and amniotic fluid. Biol Trace Elem Res 2000 Jan;73(1):47-54.

24. Little RE, Gladen BC. Levels of lipid peroxides in uncomplicated pregnancy: a review of the literature. Reprod Toxicol 1999 Sep-Oct;13(5):347-352. 